\title{
Partial Amino Acid Sequence
}

\section{Homology between an Heredofamilial Amyloid Protein and Human Plasma Prealbumin}

\author{
Merrill D. Benson, Rheumatology Section, Indianapolis Veterans \\ Administration Medical Center and Division of Rheumatology, \\ Department of Medicine, Indiana University School of Medicine, \\ Indianapolis, Indiana 46223
}

\begin{abstract}
A B S T R A C T Amyloid fibril protein has been isolated from the tissues of a patient of Swedish ancestry with autosomal dominant heredofamilial amyloidosis. After solubilization in guanidine $\mathrm{HCl}$, a significant amount of the protein was contained in a homogeneous low molecular weight fraction. Molecular weight of $\sim 14,000$, amino acid analysis, double immunodiffusion analysis and immunoelectrophoresis all supported this material being a prealbumin-related protein. Automated sequence analysis gave a mixture of amino acids at each step, suggesting an heterogeneous $\mathrm{NH}_{2}$-terminus. After cleavage of the protein with cyanogen bromide, a homogeneous peptide was obtained with the sequence Val-Val-Val-Leu-Asp-Ala-Val-Arg-GlyThr-Pro- corresponding in 9 of the 11 positions analyzed with the known sequence of human prealbumin, starting with position 14 .

Antiserum raised to the amyloid protein reacted with normal human prealbumin. After absorption with normal human serum, this antiserum continued to detect a determinant in the amyloid patient's serum, suggesting an abnormal serum prealbumin, which may be the precursor of the fibril protein in this type of heredofamilial amyloidosis. Indirect immunohistochemical studies on kidney tissue from the patient with amyloidosis showed marked staining with anti-prealbumin and anti-heredofamilial amyloid protein, but not with antiAA or anti-kappa antisera. No genetic association between this family with amyloidosis and Portuguese families with familial amyloid polyneuropathy is known.
\end{abstract}

\footnotetext{
Dr. Benson is the recipient of U.S. Public Health Research Career Development Award 1 K04 AM00352 from the National Institute of Arthritis, Metabolism and Digestive Diseases.

Received for publication 14 October 1980 and in revised form 1 December 1980.
}

Prealbumin is a tightly structured protein with an extensive $\beta$-structure. Amino acid substitutions as reported here may be the basis for altered metabolism and amyloid fibril formation.

\section{INTRODUCTION}

The systemic amyloidoses are characterized by the deposition of proteinaceous material composed in large part of fibrils having a beta-pleated sheet configuration (1). These fibril proteins all bind Congo red to give a characteristic green birefringence when viewed between cross polars. Biochemical analyses of amyloid fibril proteins over the last $10 \mathrm{yr}$ have shown that a number of proteins or fragments of proteins can form fibrils which exhibit the histologic and physical chemical properties of amyloid (2-5). Primary amyloid and amyloid deposits associated with multiple myeloma and Waldenström's macroglobulinemia are composed in large part of fragments of immunoglobulin light chains (2). Classical secondary amyloidosis associated with chronic inflammatory diseases has deposits that are composed of amyloid A (AA), ${ }^{1}$ a degradation product of an acute phase reactant, serum AA (SAA) $(6,7)$. A third commonly recognized type of systemic amyloidosis is seen with the heredofamilial syndromes (8).

The heredofamilial amyloidoses represent a variety of syndromes which demonstrate autosomal dominant modes of inheritance and for the main part present as polyneuropathies (9). Each syndrome has unique clinical features related to age of onset and distribution of organ involvement. In the past the hereditary amyloidoses have been classified according to the clinical syndrome and to the country or ethnic group in which

\footnotetext{
${ }^{1}$ Abbreviations used in this paper: AA, amyloid A protein; SAA, serum AA.
} 
they were first described. Genetic studies in general have failed to show connections between the different syndromes.

Recently, Costa et al. (10) presented evidence that the amyloid deposits in Portuguese familial amyloid polyneuropathy, which was first described by Andrade (11), have prealbumin as a major constituent. This was the first report of biochemical characterization of an heredofamilial amyloid protein other than the AA protein associated with familial Mediterranean fever (6). The biochemical studies on the Portuguese form of amyloid give a basis for comparison of other forms of heredofamilial amyloidosis.

We have studied a family with hereditary amyloidosis that is manifested as peripheral neuropathy, nephropathy, and cardiomyopathy (12). One member of this kindred recently died after $4 \mathrm{yr}$ of chronic renal dialysis. His tissues were made available for the chemical studies which are the subject of the present report.

\section{METHODS}

Isolation of amyloid fibrils. Amyloid fibrils were isolated from kidney tissue by repeated homogenization in normal saline and centrifugation as previously described $(13,14)$.

Fractionation of the fibrils. Amyloid fibrils (100 mg) were solubilized in $6 \mathrm{M}$ guanidine hydrochloride buffered with $0.5 \mathrm{M}$ Tris, $\mathrm{pH} 8.5$, and $0.002 \mathrm{M}$ EDTA, reduced and alkylated with dithiothreitol and iodoacetamide, and fractionated on Sephadex G-100 in $4 \mathrm{M}$ guanidine-1 N acetic acid. Fractionations were also done without reduction and alkylation.

Amino acid analysis. Each protein fraction was hydrolyzed in $6 \mathrm{~N} \mathrm{HCl}$ under nitrogen in sealed tubes for $22 \mathrm{~h}$ at $110^{\circ} \mathrm{C}$. Analyses were performed on a Beckman $119 \mathrm{C}$ amino acid analyzer (Beckman Instruments, Fullerton, Calif.).

Polyacrylamide gel electrophoresis. Discontinuous electrophoresis was performed in $0.1 \%$ sodium dodecyl sulfate according to Weber and Osborn (15), utilizing $12.5 \%$ acrylamide gel. Molecular weight standards included phosphorylase b $(94,000 \mathrm{~mol} \mathrm{wt})$, bovine serum albumin $(68,000)$, ovalbumin $(45,000)$, carbonic anhydrase $(30,000)$, and lysozyme $(14,300)$ (Bio-Rad Laboratories, Richmond, Calif.). Additional standards were cytochrome $c(12,384)$ (Sigma Chemical Co., St. Louis, Mo.) and human protein AA $(8,400)$.

Amino acid sequence. Amino acid sequencing was done on a Beckman automated sequencer (Model 890C, Beckman Instruments, Inc., Spinco Div., Palo Alto, Calif.) by the method of Edman and Begg (16). Phenylthiohydantoin amino acids were identified with high pressure liquid chromatography, gas chromatography, and back hydrolysis with subsequent amino acid analysis.

Immunologic studies. Antisera were raised in New Zealand white rabbits by injection in foot pads and intradermally of guanidine-solubilized amyloid fibrils in complete Freund's adjuvant (Difco Laboratories, Detroit, Mich.). Intradermal boosts were given at monthly intervals, and serum was obtained 1 wk after the last boost.

Double immunodiffusion studies were performed in $0.6 \%$ agarose gels (17). Immunoelectrophoresis was performed on an LKB Multiphor System (LKB Instruments, Rockville, Md.) and plates were stained with coomassie brilliant blue. Commercial antisera to human proteins IgG, IgA, IgM, IgD, kappa chain, lambda chain, retinol binding protein, C-reactive protein, and prealbumin were obtained from Behring Diagnostics,
Somerville, N. J. Antisera to IgG, IgA, IgM, IgD, kappa chain, and lambda chain were also obtained from Meloy Laboratories Inc., Springfield, Va. Antiserum to human P-component, Creactive protein, and prealbumin were obtained from Atlantic Antibodies, Westbrook, Maine.

Immunofluorescent staining. Indirect immunofluorescent staining was done using rabbit antihereditary amyloid fibril antibody and rabbit antiprealbumin (Behring Diagnostics, Somerville, N. J.). Fluorescein-labeled goat anti-rabbit IgG was used as the second antibody (Meloy Laboratories, Springfield, Va.). Sections of kidney that had been snap-frozen in dry ice-acetone and stored at $-70^{\circ} \mathrm{C}$ were prepared on a cryostat (Damon/IEC Division, Needham Heights, Mass.). Sections were overlaid for $30 \mathrm{~min}$ at room temperature with antiserum previously absorbed with liver powder, washed three times with phosphate-buffered saline, and then overlaid with the fluorescein-labeled second antibody. After washing three times in phosphate buffered saline, sections were mounted in glycerol and observed in a Zeiss microscope fitted with a vertical illuminator (Carl Zeiss, Inc., New York). Control sections of normal human kidney and kidney from a patient with primary amyloidosis were treated in the same fashion as kidney tissue from the patient with hereditary amyloidosis. Sections of all three kidney specimens were treated with anti-human AA and anti-human immunoglobulin kappa chain as controls for the staining procedure.

\section{RESULTS}

Congo red-stained sections of formalin-fixed tissue obtained at the time of autopsy showed extensive involvement of kidney, peripheral nerve, and thyroid with amyloid deposits. Kidney tissue was used for extraction of fibrils because of the heavy infiltration with amyloid. After repeated homogenization and centrifugation, two layers were apparent in the saline-insoluble material. A typical extraction procedure of $20 \mathrm{~g}$ of fresh-frozen tissue gave $293 \mathrm{mg}$ of top layer material and $1,265 \mathrm{mg}$ of bottom layer material. Extraction of the saline-insoluble material with distilled water failed to give the fibril suspension that is characteristic of most primary and secondary amyloids, as noted by Pras et al. (13). Congo red staining of the top layer and bottom layer materials showed very positive staining of the top layer material but also considerable Congo red staining of the bottom layer material.

After solubilization in $6 \mathrm{M}$ guanidine hydrochloride chromatography of the top layer material on Sephadex G-100 gave a void volume peak with a shoulder on the descending limb, plus a retarded peak (Fig. 1). The void volume peak was labeled GI, the shoulder peak GII, and the retarded peak GIII. Each of the peaks from Sephadex G-100 was dialyzed exhaustively against distilled water and lyophilized. Peak GIII consistently represented $\sim 30 \%$ of the recovered protein. Reduction with dithiothreitol did not significantly change profiles or yields. Normal human kidney obtained from a patient who suffered accidental drowning was extracted in a manner similar to the amyloid tissue as a control. No retarded material comparable to peak GIII was noted in the normal kidney material (Fig. 1). Fractions from the 


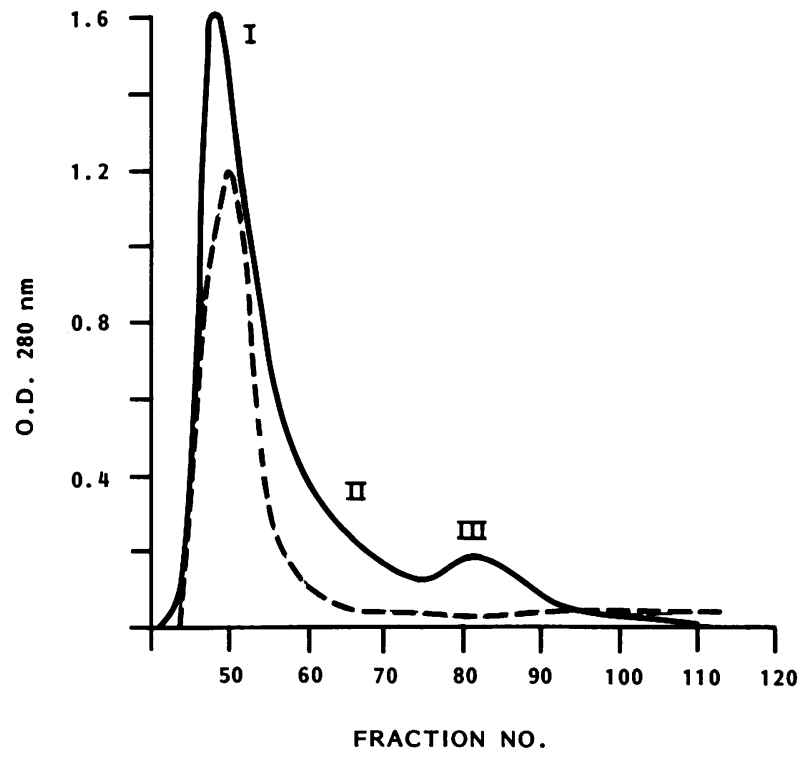

FIGURE 1 Chromatogram of amyloid top layer material on Sephadex G-100 column $(2.6 \times 90 \mathrm{~cm})$ (solid line). Chromatogram of normal human kidney material (dash line) did not show any retarded peak.

chromatography of the normal human kidney corresponding to the retarded peaks of the amyloid material were pooled, dialyzed, and lyophilized for immunodiffusion studies. Polyacrylamide gel electrophoresis in sodium dodecyl sulfate of the GIII material gave only one band (Fig. 2). Molecular weight of GIII determined

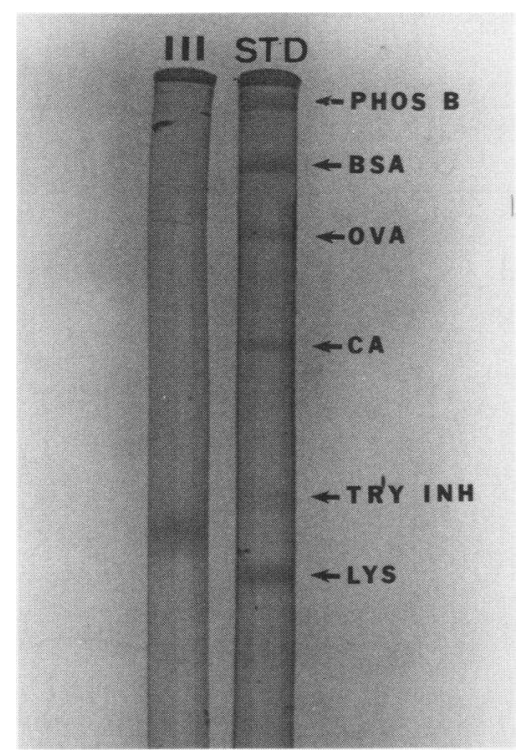

Figure 2 Polyacrylamide gel electrophoresis in $0.1 \%$ sodium dodecyl sulfate of amyloid peak GIII material (III). Only one band is seen, with a molecular weight of $\sim 14,000$ determined by comparison with standards (STD). by comparison with molecular weight standards in $12.5 \%$ acrylamide ranged between 13,500 and 15,000 on several determinations. Sodium dodecyl sulfatepolyacrylamide gel electrophoresis of GII showed major bands at 30,000 and 34,000 daltons plus a minor band at 14,000 daltons. GI demonstrated multiple high molecular mass bands.

Antiserum to the guanidine-solubilized amyloid fibrils gave a strong line against GIII material. This antiserum also gave a single line against GI and GII and showed complete identity with GIII material (Fig. 3). This finding suggests that even after solubilization in $6 \mathrm{M}$ guanidine, GIII material continues to be present in higher molecular weight fractions. This antiserum also gave a single line with serum from the amyloid patient and this line showed complete identity with GIII material (Fig. 4). A single line was also seen with normal human serum; however, multiple double diffusion analyses of several normal human sera showed a spur of the GIII line over the normal human serum line (Fig. 4). Absorption of anti-GIII with normal human serum coupled to Sepharose 4B removed the reaction with normal human serum, but did not completely remove the reactivity with GIII. This suggested that GIII contained an antigenic determinant not present in the normal human serum, but present in the serum from the patient whose amyloid was the subject of this study. Analysis of serum from the brother of the patient studied here who also had hereditary amyloidosis gave similar findings (12).

Immunoelectrophoresis of GIII material vs. antihuman serum showed a single line in the prealbumin range. Immunoelectrophoresis of GIII material using antiserum to the hereditary amyloid gave a similar line, and this antiserum also detected a single line in the prealbumin range of normal human serum. Commercial

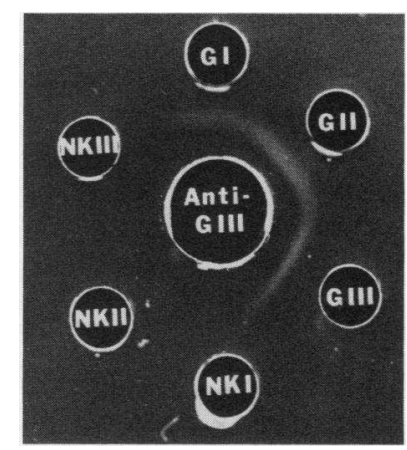

FIGURE 3 Double immunodiffusion in agarose of fractions from Sephadex G-100 chromatography of amyloid substance (GI, GII, GIII) and corresponding fractions from Sephadex G-100 chromatography of normal human kidney (NKI, NKII, NKIII) vs. antiserum raised to the amyloid substance. A line of completed identity is seen between fractions GI, GII, and GIII. No reaction is seen with normal human kidney fractions. 


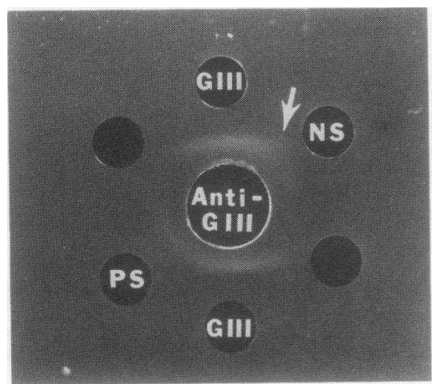

FIGURE 4 Double immunodiffusion analysis in agarose of amyloid fraction GIII and serum from amyloid patient and normal human serum. A line of complete identity is seen with GIII material and the amyloid patient's serum (PS). A line of partial identity is seen between GIII material and normal human serum (NS) with a small spur of the GIII line over the normal human serum line (arrow).

anti-prealbumin reacted with GIII to give a similar line. GIII, however, migrated slightly faster than normal human serum prealbumin (Fig. 5).

Material GIII was tested in double diffusion analysis against a number of commercial antisera. Antisera to normal human serum kappa chain, lambda chain, IgG, IgA, IgM, IgD, amyloid P-component, AA, C-reactive protein, retinol-binding protein, albumin, betalipoprotein, alpha-2-macroglobulin, haptoglobin, ceru-

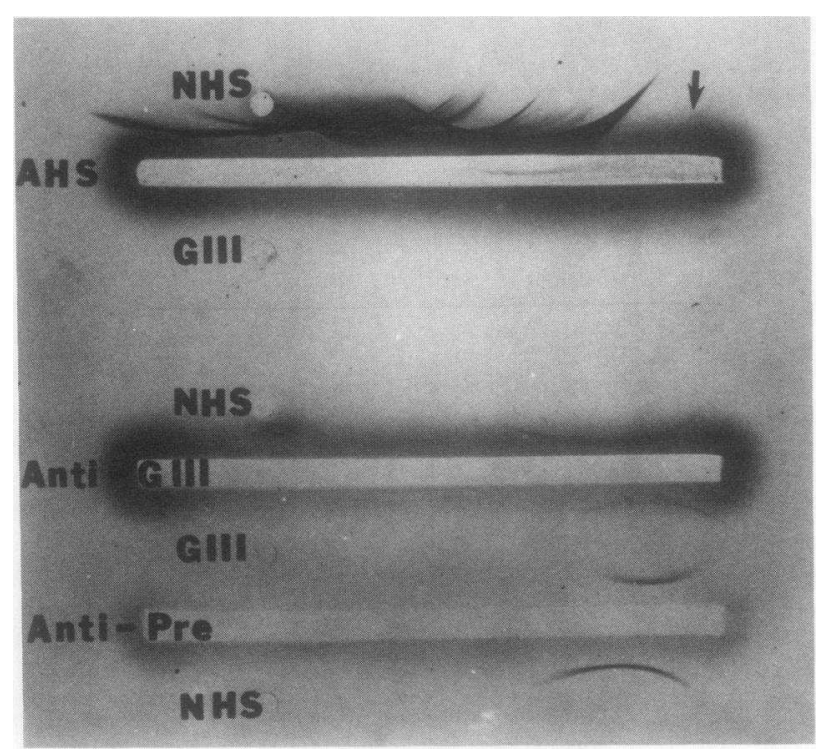

FIGURE 5 Immunoelectrophoresis of amyloid GIII material against anti-human serum (AHS), anti-GIII amyloid substance, and anti-prealbumin (anti-PRE). AHS gives a single line against GIII, which corresponds to the prealbumin line of normal human serum (NHS) (arrow). Anti-GIII gives a single line against NHS corresponding to the prealbumin line. Anti-PRE gives a single line against GIII and against NHS. The GIII material migrates slightly faster than prealbumin in NHS. loplasmin, and alpha-1-antitrypsin gave no reaction with GIII. Anti-prealbumin gave a single line against GIII material and this line showed complete identity with a line in normal human serum. Antiserum to heredofamilial amyloid GIII gave no lines against normal kidney fractions from Sephadex G-100 chromatography (Fig. 3).

Amino acid analyses of the amyloid top layer material and GIII from Sephadex G-100 chromatography are listed in Table I. Compared with published data for prealbumin, lower amounts of threonine and valine and higher amounts of arginine and leucine were found in GIII.

Amino terminal amino acid sequencing of GIII material gave a mixture of amino acids at each step. Since it is known that prealbumin has only one methionine (located at position 13 from the $\mathrm{NH}_{2}$-terminus), GIII was subjected to $\mathrm{CNBr}$, which cleaves only at methionine residues (18). After cleavage of GIII with $\mathrm{CNBr}$, chromatography on Sephadex G-75 in 10\% formic acid gave two peaks, one near the void volume and the other corresponding to a molecular weight less than 15,000 . Sequence analysis of each peak gave identical results suggesting that the higher molecular weight peak represented aggregated GIII (Table II). 9 of the 11 residues analyzed were homologous with the known human prealbumin sequence starting with position 14 .

Indirect immunofluorescent studies on kidney snap-frozen at the time of autopsy showed marked localization in glomeruli, around tubules and in blood vessel walls using both antiserum to GIII (Fig. 6a) and

TABLE I

Amino Acid Analyses

\begin{tabular}{lrrr}
\hline & $\begin{array}{c}\text { Whole amyloid } \\
\text { fibrils }\end{array}$ & GIII & Prealbumin* \\
\hline \multicolumn{3}{c}{ residues 1,000 residues } \\
Aspartic acid & \multicolumn{3}{c}{} \\
Threonine & 80.7 & 76.4 & 64 \\
Serine & 53.2 & 69.4 & 96 \\
Glutamic acid & 60.7 & 72.7 & 88 \\
Proline & 112.6 & 118.2 & 96 \\
Glycine & 67.4 & 50.5 & 64 \\
Alanine & 157.2 & 96.6 & 80 \\
Half-cystine & 87.5 & 98.0 & 96 \\
Valine & 14.0 & 5.9 & 8 \\
Methionine & 58.9 & 77.9 & 96 \\
Isoleucine & 13.4 & 5.0 & 8 \\
Leucine & 36.0 & 41.8 & 40 \\
Tyrosine & 73.0 & 73.2 & 56 \\
Phenylalanine & 30.6 & 30.9 & 40 \\
Lysine & 34.2 & 37.3 & 40 \\
Histidine & 48.4 & 65.4 & 64 \\
Arginine & 22.0 & 28.9 & 32 \\
& 50.3 & 51.8 & 32 \\
\hline
\end{tabular}

* Calculated from sequence data (22). 
TABLE II

Amino Acid Sequence of GIII-CNBr

\begin{tabular}{|c|c|}
\hline Prealbumin $(21)$ & $\begin{array}{cccccccccccc}1 & 2 & 3 & 4 & 5 & 6 & 7 & 8 & 9 & 10 & 11 & 12 \\
\text { Gly-Pro-Thr-Gly-Thr-Gly-Glu-Ser-Lys-Cys-Pro-Leu- }\end{array}$ \\
\hline \multicolumn{2}{|l|}{ GIII-CNBr } \\
\hline Prealbumin & $\begin{array}{cccccccccccc}13 & 14 & 15 & 16 & 17 & 18 & 19 & 20 & 21 & 22 & 23 & 24 \\
\text { Met-Val-Lys-Val-Leu-Asp-Ala-Val-Arg-Gly-Ser-Pro- }\end{array}$ \\
\hline GIII-CNBr & Val-Val-Val-Leu-Asp-Ala-Val-Arg-Gly-Thr-Pro- \\
\hline
\end{tabular}

commercially obtained anti-prealbumin (Fig. 6b). Control sections from normal human kidney and kidney from a patient with primary amyloidosis failed to show similar localization of fluorescent stain. Hereditary amyloid kidney sections failed to stain with anti-AA and anti-kappa chain (Fig. 6c and 6d).

\section{DISCUSSION}

The amyloid characterized by these studies is from a patient of Swedish origin (12). Extensive genetic studies have failed to reveal connection with any of the several kindreds with amyloidosis in the United States or with Portuguese kindreds (8).

The relatively low yield of top layer material, the finding of Congo red positive material in the bottom layer material, and the negligible amount of fibrils isolated after water extraction indicate that the heredofamilial amyloid fibrils are much more resistant to the standard method of extraction than are most amyloid deposits of primary or secondary types (13). Approximately $40 \%$ of the top layer material was recovered as insoluble residue after fractionation in $6 \mathrm{M}$ guanidine. This is comparable to the amount of insoluble residue found in fibril preparations of many secondary amyloid tissues $(19,20)$ and may reflect an inability of guanidine to solubilize completely the amyloid fibrils.

The studies of GIII employing amino acid analysis, double immunodiffusion analysis, immunoelectrophoresis, and molecular weight determination are consistent with this material being related to a subunit of prealbumin. The amino acid sequence studies of GIII prove the relationship to prealbumin. Since no polymorphism has previously been reported in human prealbumin, the finding of 2 out of 11 residue substitutions was unexpected. The substitution of valine for lysine at position 15 , however, does give a charge change which might explain the altered mobility of the GIII protein in electrophoresis. The threonine/serine substitution at position 23 was confirmed by a second run with monitoring of the high pressure liquid chromatography at 213 as well as $254 \mathrm{~nm}$. This substitution represents a single base change.
Despite the low yield of the prealbumin-related peptide from the amyloid starting material, two findings strongly suggest that it is a significant component of the amyloid deposits. The first, as noted also by Costa et al. (10) is that extracts of the amyloid material failed to react with antisera to many human serum components. This is good evidence against prealbumin being present merely as a non-specific component. The second is the immunohistochemical staining. Strong staining of the glomerular deposits by antiprealbumin and anti-GIII without staining by anti-AA and anti-kappa chain, both of which react with normal human serum constituents, indicates that prealbumin antigenic determinants are an integral part of the amyloid deposits in situ.

The finding of a prealbumin peptide as a major constituent of another type of heredofamilial amyloid was unexpected. This raises the obvious question of whether all forms of autosomal dominant inherited amyloidosis contain prealbumin, and if so, what the variables are that give different phenotypic expression to these amyloidoses.

Prealbumin exists in serum as a 54,980-dalton molecule composed of four identical subunits of $\sim 14,000$ daltons (21). Molecular weight determinations of GIII material suggest that the whole polypeptide chain may be incorporated into fibrils, although the sequence analysis suggests some degradation at the amino terminus. Antiserum to retinol-binding protein, which is normally linked to prealbumin in serum, failed to detect antigenic determinants of this protein in the amyloid fractions.

The complete amino acid sequence of prealbumin is known (22). It has an extensive $\beta$-structure, a property it shares with immunoglobulin light chains (23). This conformation may be one of the variables required to form fibrils. Prealbumin also forms a tight complex with retinol-binding protein, the serum transport protein for retinol, and therefore has a protein-lipid association (24). In this regard it may be similar to protein AA which is now known to bind to high density lipoprotein (25).

Little is known about the transfer of retinol from the prealbumin-retinol-binding protein complex to the tissue target. Both the Portuguese familial amyloid 

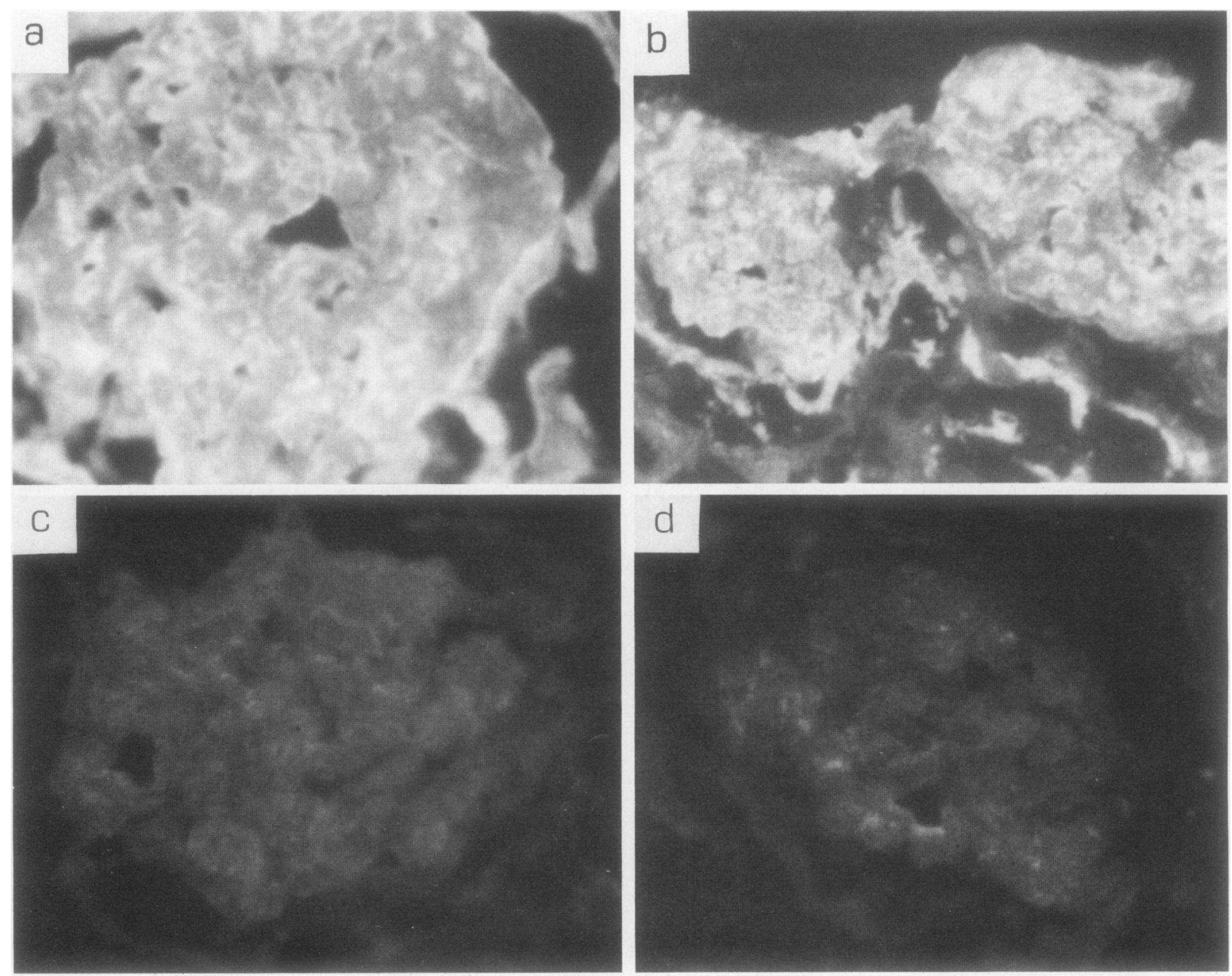

FIGURE 6 Immunofluorescent stain of heredofamilial amyloid kidney with (a) anti GIII (b) antiprealbumin, (c) anti-human AA, and (d) anti-kappa. Intense staining of glomeruli is seen with anti-GIII and anti-prealbumin but not with anti-AA or anti-kappa. Upper left: immunofluorescent stain of amyloid kidney with anti-GIII showing intense localization of stain to the glomerulus. Original magnification $\times 400$. Upper right: immunofluorescent stain of heredofamilial amyloid kidney with anti-prealbumin showing localization in glomeruli and some staining of interstitial structures. Blood vessels were also markedly stained. Original magnification $\times 250$. Lower left: section of heredofamilial amyloid kidney treated with anti-human AA. Amyloid deposits are not stained. Lower right: section of heredofamilial amyloid kidney treated with anti-kappa chain. Amyloid deposits are not stained.

polyneuropathy and the kindred studied here have vitreous deposits of amyloid $(11,26)$. It could be speculated that prealbumin involved in transport of retinol to the eye might, over many years time, add to local deposition of fibrils.

Ouchterlony analysis using anti-GIII suggests that this antiserum recognizes a determinant of GIII material which is present in the serum prealbumin of the two affected members of this kindred, but which is not present in normal human serum. This finding is consistent with a structural variation in the prealbumin of this kindred, but at the present time cannot be definitely ascribed to the identified amino acid substitutions.
Polymorphism of prealbumin has previously been described in rhesus monkeys (27). Data presented by Alper et al. suggest codominant alleles in the rhesus monkey which code for different prealbumin monomers. Polymorphism in human prealbumin has not been previously demonstrated. Whether either of the two changes in the amino acid sequence determined thus far account for the predisposition for amyloid fibril formation cannot be said. Further sequence analysis of the amyloid protein and the presumed abnormal serum prealbumin from this family will, it is hoped, answer this question.

At this point one can only speculate on the presence 
of prealbumin-related proteins in other types of heredofamilial amyloidosis. If a number of variables are involved in fibril formation, these could explain the phenotypic variations in the many kindreds. On the other hand, other serum proteins that have major degrees of beta configuration in the native state might, under proper conditions, lead to fibril formation.

\section{ACKNOWLEDGMENTS}

The author thanks Dr. Brooke Alt for help in obtaining material, William Kuster and Marilyn Smith for technical assistance, and Patricia Rusie for secretarial assistance. The author also thanks Dr. J. Donald Capra for performing the amino acid sequence studies.

This work was supported by grants from the Veterans Administration Medical Center (MRIS 583-0888), U. S. Public Health Service, National Cancer Institute, (1 R01 CA22141), National Institute of Arthritis, Metabolism, and Digestive Diseases (AM 20582), The Arthritis Foundation, and The Grace M. Showalter Foundation.

\section{REFERENCES}

1. Glenner, G. G., E. D. Eanes, H. A. Bladen, R. P. Linke, and J. D. Termine. 1974. $\beta$-pleated sheet fibrils. A comparison of native amyloid with synthetic protein fibrils. J. Histochem. Cytochem. 22: 1141-1158.

2. Glenner, G. G., W. Terry, M. Harada, C. Isersky, and D. Page. 1971. Amyloid fibril proteins: Proof of homology with immunoglobulin light chains by sequence analyses. Science (Wash. D. C.). 172: 1150-1151.

3. Benditt, E. P., N. Erikson, M. A. Hermodson, and L. H. Ericsson. 1971. The major proteins of human and monkey amyloid substance: common properties including unusual N-terminal amino acid sequences. FEBS (Fed. Eur. Biochem. Soc.) Lett. 19: 169-173.

4. Sletten, K., P. Westermark, and J. B. Natvig. 1976. Characterization of amyloid fibril proteins from medullary carcinoma of the thyroid. J. Exp. Med. 143: 993-997.

5. Westermark, P., J. B. Natvig, and B. Johansson. 1977. Characterization of an amyloid fibril protein from senile cardiac amyloid. J. Exp. Med. 146: 631-636.

6. Levin, M., M.Pras, and E. C. Franklin. 1973. Immunologic studies of the major nonimmunoglobulin protein of amyloid. I. Identification and partial characterization of a related serum component. J. Exp. Med. 138: 373-380.

7. Husby, G., and J. B. Natvig. 1974. A serum component related to nonimmunoglobulin amyloid protein AS, a possible precursor of the fibrils. J. Clin. Invest. 53: 1054-1061.

8. Andrade, A., S. Araki, W. D. Block, A. S. Cohen, C. E. Jackson, Y. Kuroiwa, V. A. McKusick, J. Nissim, E. Sohar, and M. W. VanAllen. 1970. Hereditary amyloidosis. Arthritis Rheum. 13: 902-915.

9. Cohen, A. S., and M. D. Benson. 1975. Amyloid neuropathy. In Peripheral Neuropathy. P. S. Dyck, P. K.
Thomas, and E. H. Lambert, editors. W. B. Saunders Co., Philadelphia, Pa. 1067-1091.

10. Costa, P. P., A. S. Figueira, and F. R. Bravo. 1978. Amyloid fibril protein related to prealbumin in familial amyloidotic polyneuropathy. Proc. Natl. Acad. Sci. U. S. A. 75: 4499-4503.

11. Andrade, C. 1952. A peculiar form of peripheral neuropathy. Familial atypical generalized amyloidosis with special involvement of the peripheral nerves. Brain. 75: 408-427.

12. Benson, M. D., and A. S. Cohen. 1977. Generalized amyloid in a family of Swedish origin. Ann. Intern. Med. 86: 419-424.

13. Pras, M., M. Schubert, D. Zucker-Franklin, A. Rimon, and E. C. Franklin. 1968. The characterization of soluble amyloid prepared in water. J. Clin. Invest. 47: 924-933.

14. Skinner, M., and A. S. Cohen. 1971. N-terminal amino acid analysis of the amyloid fibril protein. Biochim. Biophys. Acta. 236: 183-190.

15. Weber, K., and M. Osborn. 1969. The reliability of molecular weight determinations by dodecyl sulfate-polyacrylamide gel electrophoresis. J. Biol. Chem. 244: 4406-4412.

16. Edman, P., and G. Begg. 1967. A protein sequenator. Eur. J. Biochem. 1: 80-91.

17. Ouchterlony, O. 1958. Diffusion in gels. Methods for immunological analyses. Progr. Allergy. 5: 1-78.

18. Gross, E. 1967. The cyanogen bromide reaction. Methods Enzymol. 11: 238-255.

19. Benson, M. D., M. Skinner, J. Lian, and A. S. Cohen. 1975. "A" protein of amyloidosis. Isolation of a cross-reacting component from serum by affinity chromatography. Arthritis Rheum. 18: 315-322.

20. Lian, J. L., M. D. Benson, M. Skinner, and A. S. Cohen. 1975. A 25,000 molecular weight protein constituent of human amyloid fibrils related to amyloid protein AA. Arch. Biochem. Biophys. 171: 197-205.

21. Gonzalez, G., and R. E. Offord. 1971. The subunit structure of prealbumin. Biochem. J. 125: 309-317.

22. Kanda, Y., D. S. Goodman, R. E. Canfield, and F. J. Morgan. 1974. The amino acid sequence of human plasma prealbumin. J. Biol. Chem. 249: 6796-6805.

23. Blake, C. C. F., M. J. Geisow, S. J. Oatley, B. Rerat, and C. Rerat. 1978. Structure of prealbumin: secondary, tertiary and quaternary interactions determined by Fourier refinement at 1.8A. J. Mol. Biol. 121: 339-356.

24. Goodman, D. S. 1976. Retinol-binding protein, prealbumin and vitamin A transport. Progr. Clin. Biol. Res. 5: 313-330.

25. Benditt, E. P., and N. Eriksen. 1977. Amyloid protein SAA is associated with high density lipoprotein from human serum. Proc. Natl. Acad. Sci. U. S. A. 74: 4025-4028.

26. Lessell, S., P. A. Wolf, M. D. Benson, and A. S. Cohen. 1975. Scalloped pupils in familial amyloidosis. N. Engl. J. Med. 293: 914-915.

27. Alper, C. A., N. I. Robin, and S. Refetoff. 1969. Genetic polymorphism of rhesus thyroxin-binding prealbumin: evidence for tetrameric structure in primates. Proc. Natl. Acad. Sci. U. S. A. 63: 775-781. 